\title{
BIBLIOTERAPI UNTUK MEREDUKSI KECEMASAN PADA KLIEN GENERAL ANXIETY DISORDER (GAD)
}

\section{BIBLIOTHERAPY TO REDUCE ANXIETY IN GENERAL ANXIETY DISORDER (GAD) CLIENTS}

\author{
Lale Agit Diah Arini', IGAA Novikayati ${ }^{2}$ \\ Psikologi Profesi (S2) Universitas 17 Agustus 1945 Surabaya \\ 1Agit.arini.lale@gmail.com; 2ekayatinovi@gmail.com
}

\begin{abstract}
GAD or generalized anxiety disorder can occur in someone who is overly anxious about their life situation. These disorders are usually overcome by providing Bibliotherapy which aims to provide information, insight into the problem, stimulate discussion about problems, communicate new values and attitudes, create awareness. This case study used 1 female 45 years of age who experienced a generalized anxiety disorder (GAD). Intervention on the subject was carried out for 30 days in 5 phases, namely book introduction, book reading, incubation, follow-up and the last phase of creative writing. The results of observations and interviews method show that bibliotherapy is effective in reducing anxiety symptoms in people with GAD (generalized anxiety disorder).
\end{abstract}

Keywords: Bibliotherapy, general anxiety disorder

\begin{abstract}
ABSTRAK
GAD (generalized anxiety disorder) atau gangguan kecemasan menyeluruh dapat terjadi pada seseorang yang mencemaskan secara berlebihan keadaan hidup mereka. Gangguan tersebut biasanya diatasi dengan memberikan Biblioterapi yang bertujuan adalah memberikan informasi, insight tentang masalah, menstimulasi diskusi tentang masalah, mengkomunikasikan nilai-nilai dan sikap - sikap baru, menciptakan suatu kesadaran. Studi kasus ini menggunakan 1 orang perempuan usia 45 tahun yang mengalami gangguan berupa GAD (generalized anxiety disorder). Intervensi pada subjek dilakukan selama 30 hari sebanyak 5 fase yakni perkenalan buku, membaca buku, inkubasi, tindak lanjut dan yang terakhir fase menulis kreatif. Hasil observasi dan wawancara menunjukkan bahwa Biblioterapi efektif untuk menurunkan gejala kecemasan pada penderita GAD (generalized anxiety disorder).
\end{abstract}

Kata kunci: Biblioterapi, generalized anxiety disorder.

\section{PENDAHULUAN}

Kecemasan memiliki beberapa tipe salah satunya yakni gangguan kecemasan menyeluruh atau GAD (generalized anxiety disorder) sebagai aalah satu tipe spesifik yang diakui oleh PPDGJ III dan DSM-V. GAD (generalized anxiety disorder) merupakan suatu gangguan kecemasan yang ditandai dengan perasaan cemas yang umum bahwa sesuatu yang buruk akan terjadi dengan timbulnya respon keterangsangan tubuh. GAD 
ditandai dengan kecemasan yang persisten yang tidak dipicu oleh suatu objek, situasi atau aktivitas yang spesifik, Freud menyebut GAD dengan istilah "mengambang bebas" (free floating). GAD merupakan suatu gangguan yang stabil, muncul pada pertengahan remaja sampai pertengahan umur dua puluhan tahun dan kemudian berlangsung sepanjang hidup (Rapee dalam Nevid, dkk, 2005).

Individu dengan GAD adalah pencemas yang kronis, mungkin mereka mencemaskan secara berlebihan keadaan hidup mereka, seperti keuangan, kesejahteraan anak-anak, dan hubungan sosial mereka. Ciri lain yang terkait adalah merasa tegang, waswas, atau khawatir, mudah lelah, mempunyai kesulitan berkonsentrasi atau menemukan bahwa pikirannya menjadi kosong, iritabilitas, ketegangan otot, dan adanya gangguan tidur, seperti sulit untuk tidur, untuk terus tidur, atau tidur yang gelisah dan kualitas tidur yang tidak memuaskan (Nevid, dkk, 2005). Meskipun GAD secara tipikal kurang intens dalam respon fisiologisnya dibandingkan dengan gangguan panik, distress emosional yang diasosiasikan dengan GAD cukup parah untuk menganggu kehidupan orang sehari-hari. GAD sering ada bersama dengan gangguan lain seperti depresi atau gangguan kecemasan lainnya seperti agoraphobia dan obsesif - kompulsif. Kriteria Diagnostik GAD menurut DSM-V (300.02), sebagai berikut:

1) Kecemasan atau kekhawatiran yang berlebihan yang timbul hampir setiap hari, sepanjang hari, terjadi sekurangnya 6 bulan, tentang sejumlah aktivitas atau kejadian (seperti pekerjaan atau aktivitas sekolah).

2) Individu sulit untuk mengendalikan kecemasan dan kekhawatiran.

3) Kecemasan diasosiasikan dengan 6 gejala berikut ini (dengan sekurangkurangnya beberapa gejala lebih banyak terjadi dibandingkan tidak selama 6 bulan terakhir), yaitu kegelisahan, mudah lelah, sulit berkonsentrasi atau pikiran kosong, iritabilitas, ketegangan otot, dan gangguan tidur (sulit tidur, tidur gelisah atau tidak memuaskan).

4) Kecemasan, kekhwatiran, atau gejala fisik menyebabkan distress atau terganggunya fungsi sosial, pekerjaan, dan fungsi penting lainnya.

5) Gangguan tidak berasal dari zat yang memberikan efek pada fisiologis (memakai obat-obatan) atau kondisi medis lainnya (seperti hipertiroid).

6) Gangguan tidak dapat dijelaskan lebih baik oleh gangguan mental lainnya 
(seperti kecemasan dalam gangguan panik atau evaluasi negatif pada gangguan kecemasan sosial atau sosial fobia, kontaminasi atau obsesi lainnya pada gangguan obsesif-kompulsif, mengingat kejadian traumatik pada gangguan stress pasca traumatik, pertambahan berat badan pada anorexia nervosa, komplin fisik pada gangguan gejala somatik atau delusi pada gangguan schizophreniaor).

Orang yang mengalami (GAD) adalah gangguan yang disebabkan oleh prosesproses berpikir yang menyimpang. Orang-orang yang menderita GAD sering kali salah mempersepsikan kejadian-kejadian yang biasa seperti menyeberang jalan merupakan sesuatu hal yang mengancam dan dikognisi mereka terfokus pada antisipasi berbagai bencana pada masa mendatang (Beck dalam Navison, Neale, \& Kring, 2004). Perhatian para pasien GAD mudah terarah pada stimulus yang mengancam (Mogg, Millar, \& Bradley dalam Davison, dkk, 2004). Terlebih lagi pasien GAD lebih terpicu untuk mengintrepetasi stimulus yang tidak jelas sebagai sesuatu yang mengancam dan untuk menilai berbagai kejadian yang mengancam lebih mungkin terjadi pada mereka (Butler \&Mathews dalam Davison, dkk, 2004). Sensitivitas pasien GAD yang sangat tinggi terhadap stimulus yang mengancam juga muncul bila stimulus tersebut tidak dapat diterima secara sadar (Bradley dkk dalam Davison, dkk, 2004).

Pandangan kognitif lain diajukan oleh Borkovec dan para koleganya bahwa (Borkovec \& Newman dalam Davison, dkk, 2004) mereka memfokuskan pada gejala utama GAD, yaitu kekhawatiran berdasarkan perspektif hukuman. Seseorang mungkin bertanya-tanya mengapa ada orang yang sering merasa khawatir karena kekhawatiran dianggap sebagai kondisi negatif yang seharusnya tidak mendorong pengulangan. Borkovec dan para koleganya mengumpulkan bukti-bukti bahwa kekhawatiran sebenarnya merupakan penguatan negatif; ia mengalihkan pasien dari berbagai emosi negatif sehingga diperkuat oleh hasil yang positif bagi individu terkait.

Bukan suatu hal yang mengejutkan, teknik-teknik kognitif juga digunakan dalam penanganan kekhawatiran kronis yang merupakan komponen utama dari penderita GAD. Kekhawatiran merupakan kejadian kognitif yang memikirkan tentang berbagai kemungkinan yang menakutkan. Pendekatan Borkovec (a.l Borkovec \& Costello dalam Davison, dkk, 2004) mengombinasikan berbagai elemen yakni Wolpe Dan Beck 
mendorong pemaparan bertingkat terhadap berbagai situasi yang menyebabkan kekhawatiran seiring pasien mencoba menerapkan keterampilan relaksasi dan analisis logis terhadap berbagai hal. Salah satu teknik kognitif yang bertujuan menyasar persefektif klien adalah Teknik Biblioterapi, dimana teknik ini memiliki beberapa tujuan yakni adalah memberikan informasi tentang masalah, memberikan insight tentang masalah, menstimulasi diskusi tentang masalah, mengkomunikasikan nilai-nilai dan sikap-sikap baru, menciptakan suatu kesadaran (awareness) bahwa orang lain berhasil mengatasi masalah yang mirip, dan memberikan solusi atas permasalahan (Baruth \& Burggraf, 1984; Griffin, 1984; dan Pardeck \& Pardeck, 1984)

\section{METODE PENELITIAN}

Penelitian ini merupakan penelitian yang menggunakan metode studi kasus (case study). Metode studi kasus sering menjadi basis untuk perkembangan teknik-teknik terapi khusus serta hipotesa tentang sifat gangguan klinis (Kazdin, 2000). Studi kasus adalah laporan atau narasi oleh terapis tentang penanganan terhadap seorang klien tunggal meskipun laporan itu bisa saja tentang keluarga atau kelompok. Dalam penelitian ini jenis studi kasus (case study) yang digunakan adalah systematic case study. Pada systematic case study ini, ada beberapa hal yang harus diperhatikan, yaitu perubahan subyek, proses dari perlakuan yang diberikan, dan proses perubahan subyek (Barker, 2001).

Subyek penelitian yaitu perempuan dewasa yang mengalami kecemasan menyeluruh atau general anxiety disorder ( GAD ) berjumlah 1 orang, yang memenuhi kriteria yakni: (1) Memiliki diagnosa general anxiety disorder ( GAD ) oleh psikiater (2) Perempuan dengan usia dewasa. (3) Mengalami gangguan terhadap hubungan sosial dan adanya pemikiran negatif (4) Bersedia menjadi subyek penelitian. Pengambilan subyek menggunakan teknik purposive sampling yang merupakan pemilihan sampel sesuai dengan yang dikehendaki (Latipun, 2008).

Instrumen dalam penelitian ini adalah laporan observasi peneliti, wawancara, dokumentasi dan asesmen psikologi menggunakan alat tes CFIT untuk mengetahui taraf intelegensi CAQ Untuk mengetahui aspek dasar struktur kepribadian klien dan instrumen tes psikologi lainnya yakni Grafis ( Baum, DAP dan HTP ) untuk Mengidentifikasi stuktur kepribadian klien serta mengetahui indikasi gejala klinis pada 
klien. Instrumen untuk mengetahui dan mengindentfikasi tingkat kecemasan klien menggunakan Skala HARS ( Hamilton Rating Scale For Anxiety). HARS (Hamilton anxiety rating scale) memiliki 14 aspek, Nursalam (2003). Adapun aspek yang tercantum dalam (Hamilton anxiety rating scale) terdiri dari 14 gejala yang tampak pada individu yang mengalami kecemasan dengan perincian sebagai berikut : (1) Perasaan cemas yakni firasat buruk, takut akan pikiran sendiri, mudah tensinggung. (2) Ketegangan adanya rasa tegang, gelisah, gemetar, mudah terganggu dan lesu. (3) Ketakutan, takut terhadap gelap, terhadap orang asing, bila tinggal sendiri dan takut pada binatang besar. (4) Gangguan tidur, sukar memulai tidur, terbangun pada malam hari, tidur tidak pulas dan mimpi buruk. (5) Gangguan kecerdasan, penurunan daya ingat, mudah lupa dan sulit konsentrasi. (6) Perasaan depresi, hilangnya minat, berkurangnya kesenangan pada hoby, sedih, perasaan tidak menyenangkan sepanjang hari. (7) Gejala somatik, nyeri pada otot-otot dan kaku, gertakan gigi, suara tidak stabil dan kedutan otot. (8) Gejala sensorik, Perasaan ditusuk-tusuk, penglihatan kabur, muka merah dan pucat serta merasa lemah. (9) Gejala kardiovaskuler munculnya takikardi, nyeri didada, denyut nadi mengeras dan detak jantung hilang sekejap. (10) Gejala pernapasan, rasa tertekan di dada, perasaan tercekik, sering menarik napas panjang dan merasa napas pendek. (11) Gejala gastrointestinal, sulit menelan, obstipasi, berat badan menurun, mual dan muntah, nyeri lambung sebelum dan sesudah makan, perasaan panas di perut. (12) Gejala urogenital, sering keneing, tidak dapat menahan keneing, aminorea, ereksi lemah atau impotensi. (13) Gejala vegetatif, mulut kering, mudah berkeringat, muka merah, bulu roma berdiri, pusing atau sakit kepala. (4) Perilaku sewaktu wawancara, gelisah, jari-jari gemetar, mengkerutkan dahi atau kening, muka tegang, tonus otot meningkat dan napas pendek dan cepat.

Analisa terkait dengan aktivitas klien secara progress positif secara pemikiran dan perilaku sebagai bentuk monitoring efektivitas Biblioterapi dapat diamati dari tabel monitoring peneliti dan laporan keluarga klien seperti anak maupun suami klien.

Secara sederhana, bibliotherapy didefinisikan sebagai penggunaan buku untuk membantu orang mengatasi masalahnya. Tujuan utama intervensi bibliotherapy pada klien adalah memberikan informasi tentang masalah, memberikan insight tentang masalah, menstimulasi diskusi tentang masalah, mengkomunikasikan nilai-nilai dan sikap-sikap baru, menciptakan suatu kesadaran (awareness) bahwa orang lain berhasil 
mengatasi masalah yang mirip, dan memberikan solusi atas permasalahan yang dirasakan oleh klien. Intervensi yang dilakukan terdiri dari 20 hingga 60 menit dalam satu sesi, dengan frekuensi dua kali dalam seminggu. Adapun prosedur dari intervensi “ Biblioterapi" adalah sebagai berikut :

Sesi 1. Go Health, Memberikan motivasi kepada klien agar terlibat secara aktif selama proses intervensi

Sesi 2. Hallo Book, Memperkenalkan Buku yang akan digunakan sebagai media untuk menurunkan GAD pada klien selama proses intervensi.

Sesi 3. Reading, Membaca dan mulai mengidentifikasikan ringkasan buku yang dibaca.

Sesi 4. Reflection, Merenungkan, mengidentifikasi dan merefleksi materi yang dibaca, dapat menemuka kesamaan masalah GAD yang dialami klien dengan tokoh yang ada pada materi bacaan klien.

Sesi 5. Sharing Together, Klien dan terapis melakukan diskusi bersama untuk menemukan " inti cerita, penyebab dan solusi atas masalah tokoh pada materi yang dibaca" oleh klien

Sesi 6. Written Merefleksi cerita dan perjuangan tokoh dalam cerita sehingga bisa dirasakan oleh klien

Sesi 7. Sekuen, Role play dengan gambar untuk mempraktekkan flow cerita dalam cerpen terutama dalam memperjuangkan solusi perasaan cemas.

Sesi 8. Trial Social, Role play dalam lingkungan sosial yang dirasa kondisi dapat memicu kecemasan klien kembali muncul.

Sesi 9. Feedbcak, Monitoring dan controlling serta diskusi

Teknik analisis data dalam penelitian ini akan dilakukan pada setiap sesi intervensi Biblioterapi berlangsung dan akan dilihat keadaan atau kondisi klien baik sebelum menjalani tahap persesi intervensi, selama menjalani terapi, maupun perkembangan klien sesudah terapi diberikan. Data - data yang akan dianalisa adalah data dari self report dan follow up dari keluarga, data dari hasil wawancara, data dari observasi selama penelitian serta pengisian tabel monitoring checklist progress baik dari klien maupun keluarga. Analisa akhir yakni meniliki hasil skor skala hars pada tahap akhir intervensi untuk mengetahui penurunan kecemasan pada klien. 


\section{HASIL PENELITIAN}

Hasil analisis data tersaji dalam data kualitatif dan visual inspection. Secara kualitatif, dapat disimpulkan bahwa Biblioterapi membawa pengaruh positif bagi klien. Klien juga menyatakan manfaat lainnya yang dapat disimpulkan sebagai berikut : (1). Go Health, Klien memiliki motivasi untuk mengikuti proses intervensi, (2). Hallo Book, Dapat mengetahui buku yang akan dibaca, tujuan dan manfaat membaca buku. (3). Reading, Klien dapat menuntaskan dan mengidentifikasi isi buku sehingga klien menyadari GAD yang diderita klien memiliki kesamaan dengan tokoh pada buku yang dibaca klien. (4). Reflection, Menemukan insight dengan menemukan kesamaan masalah GAD yang dialami klien dengan tokoh yang ada pada materi bacaan klien. (5). Sharing Together, Klien mendapatkan insight positif atas “GAD” yang dimilikinya melalui diskusi bersama dengan terapis. (6). Written Merefleksi cerita dan perjuangan tokoh dalam cerita sehingga bisa dirasakan oleh klien. (7). Sekuen, Role play dengan gambar untuk mempraktekkan flow cerita dalam cerpen terutama dalam memperjuangkan solusi perasaan cemas. (8). Trial Social, Role play dalam lingkungan sosial yang dirasa kondisi dapat memicu kecemasan klien kembali muncul. (9). Feedbcak, Monitoring dan controlling serta diskusi.

Analisis kuantitatif dilakukan dengan visual inspection berdasarkan hasil analisis deskriptif mean empirik pada skala HARS klien. Dari analisis dapat disimpulkan bahwa klien mengalami penurunan kecemasan menyeluruh yang signifikan. Berikut hasil dari monitoring dan skor Pre dan Post Skala HARS dengan 14 aspek kecemasan :

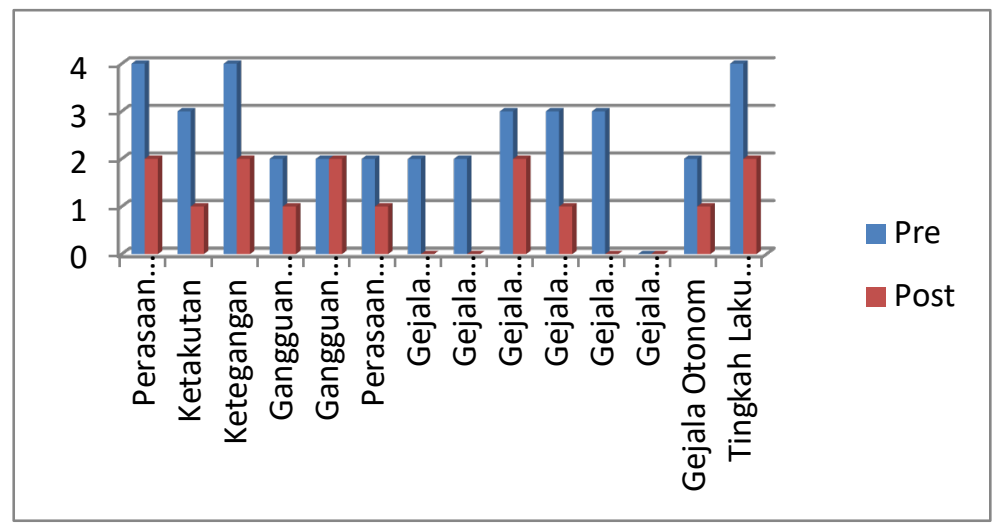

Gambar 1. Grafik Skala Hars 


\section{DISKUSI}

Sheridan, Baker \& de Lissovoy V (1984) menyatakan bahwa tujuan utama bibliotherapy adalah memberikan informasi tentang masalah, memberikan insight tentang masalah, menstimulasi diskusi tentang masalah, mengkomunikasikan nilai-nilai dan sikap-sikap baru, menciptakan suatu kesadaran (awareness) bahwa orang lain berhasil mengatasi masalah yang mirip, dan memberikan solusi atas. Banyak informasi dapat diperoleh melalui kegiatan membaca bersama dan membaca buku yang ditugaskan. Bibliotherapy membuat seseorang dapat mempelajari fakta-fakta baru, cara berbeda dalam memandang/mendekati masalah, dan pilihan cara memikirkan masalah (Griffin, 1984). Karena pengetahuan atau pengalaman pribadi sebagian besar klien tentang masalah yang mereka hadapi terbatas, bibliotherapy dapat memberikan insight yang bermanfaat bagi klien untuk mengatasi masalah-masalah tersebut.

Teknik Biblioterapi yang diberikan efektif untuk restrukturisasi kognitif membantu klien BQ merubah pikiran ne-gatifnya menjadi alternatif pikiran yang lebih rasional dan positif. Dari 14 aspek gejala kecemasan klien memiliki skor paling tinggi yakni pada angka 4 kategori berat sekali yang meliputi aspek perasaan cemas, ketakutan serta tingginya skor pada proses interview dan observasi. Sementara untuk skor ketegangan, gangguan tidur, gangguan kecerdasan, perasaan depresi, gejala somatik baik otot maupun sensorik, gejala kardiovaskuler, gejala respiratori, gejala gastrointestinal, dan gejala otonom berada pada skor 3 dengan kategori berat. Sedangkan utnuk gejala urogenital memiliki skor 0 dengan kategori tidak ada. Dari hasil skoring semua aspek klien memiliki skor 36 dimana kategori kecemasan yang dimiliki klien termasuk dalam kecemasan berat.

Pada proses asesmen awal klien memiliki skor 36 dan setelah klien mengikuti intervensi ketika kecemasan klien diukur kembali menggunakan HARS terdapat penurunan hasil pengukuran yakni dengan skor 14 dengan skor ini mengklasifikasian bahwa klien berada pada taraf kecemasan ringan, untuk detail skor perasaan cemas, gejala kardiovaskuler, dan perilaku yang muncul mengalami penurunan pada skor 2, sementara skor ketegangan, somatik, depresi, repiratori, gejala otonom, cukup baik dimana skornya diangka 1 . Untuk skor aspek kecerdasan masih belum terjadi penurunan karena klien merasa masih belum bisa terlalu fokus jika ada suara gaduh 
dan lain - lain. Dari proses intervensi yang sudah dilaksanakan klien cukup nyaman mulai dari asesmen hingga intervensi berlangsung.

Intervensi dengan Terapi Biblioterapi merupakan salah satu terapi yang menggunakan pendekatan kognitif perilaku. Teknik Biblioterapi merupakan cara untuk membantu klien dalam mengubah pikiran, perasaan, dan perilaku klien ketika membaca sebuah buku, cerita pendek atau materi yang berkaitan dengan gangguan yang dialami oleh klien. Teknik Biblioterapi juga menjadi salah satu cara untuk memodifikasi cara berpikir ( Seligman \& Reichenberg, 2002) Biblioterapi juga mempengaruhi kehidupan dengan membantu klien menemukan kesenangan dalam membaca dan melepaskan dari sidtres mental ( Brewster, 2008).

Sesuai dengan acuan dari Seligman \& Reichenberg intervensi Biblioterapi dapat membantu klien untuk dapat mengontrol perilaku kecemasan yang mulai muncul ketika klien sendiri maupun ditempat ramai. Dalam proses intervensi yang berlaku sebagai monitor kemunculan perilaku positif adalah klien sendiri dimana klien lebih mengutamakan motivasi kebersyukuran positif, keinginan untuk sembuh serta peningkatan sisi spiritual. Guna mempertahankan perlaku positif klien diharapkan dapat terus mempertahankan mengutamakan motivasi kebersyukuran positif, keinginan untuk sembuh, peningkatan sisi spiritual serta tetap ikut kegiatan disekitar lingkungan tempat tinggal maupun lingkungan kerja klien agar dapat terbiasa dengan aktivitas klien seperti biasanya.

\section{KESIMPULAN DAN SARAN}

Terapi Biblioterapi efektif untuk menurunkan kecemasan pada klien General Anxiety Disorder. Hal ini terlihat dari penurunan kecemasan klien dalam menjalan aktifitas sehari - hari seperti klien sudah mampu beraktifitas dengan normal tanpa harus membawa air mineral, dapat bersosialisasi dengan tetangga klien serta perasaan cemas klien sudah berkurang. Penurunan kecemasan pada klien juga terlihat dari hasil pengukuran HARS (Hamilton anxiety rating scale) dengan 14 aspek kecemasan) sebelum dan sesudah intervensi biblioterapi diberlakukan pada klien dimana klien dapat menerapkan roleplay dari cerita pada artikel yang dipelajari sehingga klien dapat menyadari harus meningkatkan kualitas hidup klien serta dapat mejalankan kegiatan baik dilingkungan kerja maupun lingkungan tempat tinggal klien. 
Beberapa saran bagi klien dengan harapan dapat dijalankan secara konsisten agar proses kesembuhannya berjalan dengan optimal:

1) Klien diharapkan mampu mempertahankan rasa tenang ketika melakukan banyak aktivitas baik dilingkan kerja maupun tempat tinggal klien dengan cukup baik.

2) Memperbanyak membaca dan berdiskusi tentang motivasi kesembuhan akan mengurangi kecemasan salah satunya dengan bersyukur

Beberapa saran bagi keluarga antara lain:

1) Keluarga memberikan support penuh dan cukup harus sabar dalam mengontrol dan mengawasi keadaan klien.

2) Keluarga memberikan ruang kepada klien untuk bercerita dan sharing akan banyak hal.

3) Orang - orang terdekat memberikan dukungan terhadap klien.

\section{DAFTAR PUSTAKA}

Barker, Chris. (2001). Cultural Studies. Theory and Practice (2nd ed.)

Cartwright-Hatton. S., Tschernitz.N., \& Gomersall. H. (2003). Social Anxiety in Children: Social Skills Deficit or Cognitive Distortion? Behaviour Research and Therapy, 20, 1-11. doi:10.1016/j.brat.2003.12.003.

Christensen, P.N., Stein, M.B., \& Christensen, A.M. (2003). Social Anxiety and Interpersonal Perception: A Social Relations Model Analysis. Behaviour Research and Therapy, 41, 1355-1371.

Corey, Gerald. 2013. Teori Dan Praktek Konseling Dan Psikoterapi. Diterjemahkan oleh E.Koswara.

Bandung: Refika Aditama.

Countur Rony. 2007. Metode Penelitian. Jakarta: PPM.

Davison, G.C., Neale J.M., \&Kring A.M. (2004). Psikologi Abnormal Edisi ke-9. Jakarta: PT Raja Grafindo Persada.

Kazdin, A.E. 2000. Enclopedia of Psychology. Volume 4, USA: American Psychology Press Publisher

Nevid, J.S, Rathus, S.A., \& Greene B. (2005). Psikologi Abnormal. Jakarta: Erlangga.

Scalabassi.(1973). Literature as a Therapuetic Tool : A Review of The Literature on Bibliotherapy. American Journal of Psychotherapy

Seligman, L. dan Reichenberg, L.W. (2010). Theories of counseling and psychotherapy.http://en.wikipedia.org/w/index.php?title=Reality_therapy \&oldid=50468933 tanggal 10 Oktober 2012

Tsiros, M.D., Sinn, N., Brennan, L., Coates, A.M., Wakley, J.W., Petkov, J., Howe, P.R.C., \& Buckley, J.D. (2008). Cognitive Behavioral Therapy Improves Diet And Body Composition In Overweight And Obese Adolescents. American Society for Nutrition, 87, 1134-1140. 